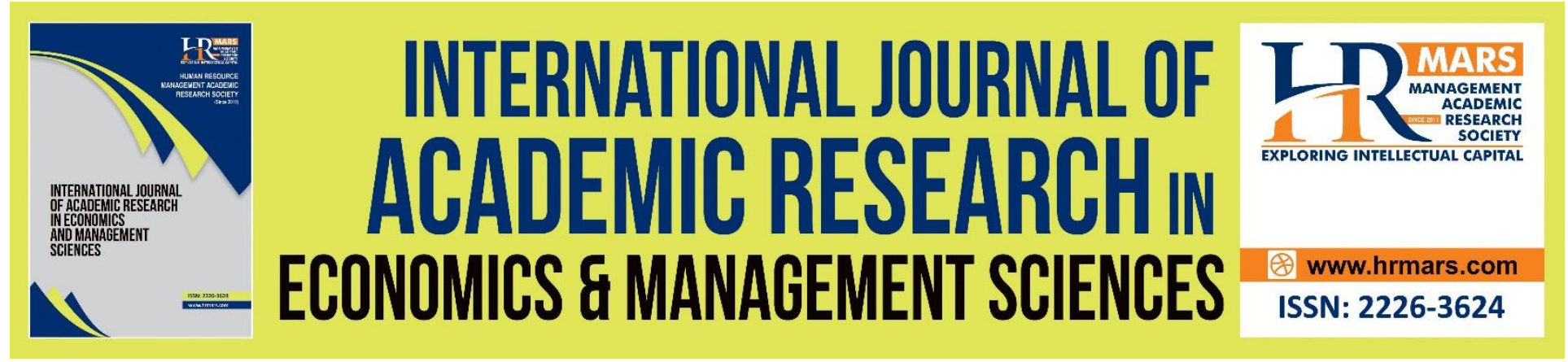

\title{
An Overview of the Health-economic Cost of Substance- abuse in Developed Countries
}

\section{Abdulmenem Ali Saleh Abu Azoum}

To Link this Article: http://dx.doi.org/10.6007/IJAREMS/v10-i2/9749

DOI:10.6007/IJAREMS/v10-i2/9749

Received: 13 September 2022, Revised: 19 October 2022, Accepted: 06 November 2022

Published Online: 26 November 2022

In-Text Citation: (Azoum, 2022)

To Cite this Article: Azoum, A. A. S. A. (2022). An Overview of the Health-economic Cost of Substance-abuse in Developed Countries. International Journal of Academic Research in Economics and Managment and Sciences, 10(2), 79-86.

Copyright: (C) 2022 The Author(s)

Published by Human Resource Management Academic Research Society (www.hrmars.com)

This article is published under the Creative Commons Attribution (CC BY 4.0) license. Anyone may reproduce, distribute, translate and create derivative works of this article (for both commercial and non-commercial purposes), subject to full attribution to the original publication and authors. The full terms of this license may be seen at: http://creativecommons.org/licences/by/4.0/legalcode

Vol. 10, No. 2, 2021, Pg. 79 - 86

http://hrmars.com/index.php/pages/detail/IJAREMS

JOURNAL HOMEPAGE

Full Terms \& Conditions of access and use can be found at http://hrmars.com/index.php/pages/detail/publication-ethics 


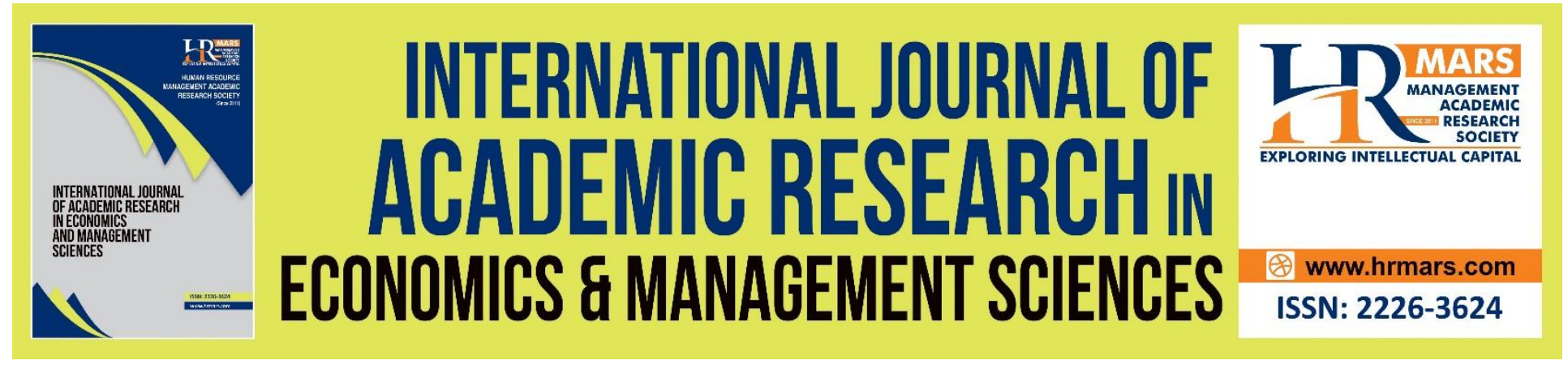

\title{
An Overview of the Health-economic Cost of Substance-abuse in Developed Countries
}

\author{
Abdulmenem Ali Saleh Abu Azoum \\ BSc in Anaesthesia and Intensive care (Tripoli University), MSc in Health and Social \\ development (Queen Margaret University), Biotechnology Research Centre, Sabha, Libya
}

\begin{abstract}
Background: Drug abuse and addiction in developed countries is a critical health concern. It is therefore important for the health sectors in these countries to monitor and attempt to limit the problem of drug abuse.

Method: A systematic review of the literature was employed as the research method for this study. Data was analysed using a thematic approach of the issues identified in the reviewed literature.
\end{abstract}

Results: Due to high rates of drug abuse, the study identified different health economic costs including a high cost of healthcare due to high morbidity and mortality, a high risk in public safety, major crimes related to substance addiction, and loss in productive hours.

Conclusion: Considering that substance abuse has such significant impacts on the economy, it is important for governments in developed countries to enforce programs to prevent and control substance abuse.

Keywords: Drugs Addiction, Substance Use, Developed Countries, Health Care Cost, Cost of Drug Treatment.

\section{Introduction}

Substance abuse and addiction are global public health concerns. These concerns may be different in the developed economic from those in developing economies (Atilola, et al., 2014). Poverty for example is associated to substance abuse in developing nations but may not be the case in developed economies. The World Health Organisation (WHO) defines substance abuse as the hazardous use of psychoactive substances (Whiteford et al., 2013). Use of psychoactive substances leads to dependence manifested in a cluster of cognitive, behavioural and physiological changes, including a strong or overwhelming desire to take the drug. Substance abuse and addiction lead to loss of control, and the abuser puts a higher priority on the use of that substance than on other obligations and activities. Addiction, which is defined as a relapsing chronic disorder, leads to persistent use despite known harmful consequences (Centers for Disease Control and Prevention, 2013). According to the National Institute of Drug Abuse, 
addiction is characterised by compulsive drug-seeking with long-lasting alterations in the brain (Edwards and Koob, 2013).

Drug dependence theories have been developed to explain drug addiction and why people keep on using illicit substances even after severe consequences. The ease of access to drugs in cities explains why their use and addiction is higher in urban areas (Sau et al., 2013). On the other hand, the disruption of illicit drug trade is associated with reduction in drug use (Dobkin, and Nicosia, 2009). Attitudinal tolerance towards substance abuse in an individual's social class and culture and among peers also explain the tendency for or against addiction. It also explains the differences in substance use rates between different classes of groups and between developed and developing economies (Patel et al., 2016). These theories highlight key issues that are associated with the health economics of substance abuse in developed countries.

The UN Office of Drugs and Crime estimates that about 15\% of people aged 15-60 are problematic users of illicit drugs in developed countries (Wang et al., 2014). The National Drug and Alcohol Research Centre at the University of New South Wales states that it is difficult to estimate the extent of substance abuse, mainly self-medicating drugs such as anabolic steroids, because the data are inadequate (Abuse and Administration Report, 2014). According to the World Health Organisation (WHO), about 300,000 deaths related to substance abuse are reported each year. This is in addition to about 2.25 million deaths caused by alcohol and tobacco abuse (Abuse and Office of the Surgeon General, 2016). Moreover, WHO insists on the implementation of the policies that influence patterns of substance use, and such policies could significantly reduce health problems that are associated with substance use. Interventions at the health care system would also be effective in the restoration of health for the affected individual.

Besides deaths resulting from drug abuse, another issue is the time of life that is lost in drug use and disability caused by drug abuse. In spite of extensive discussions and studies on the health impacts of drug abuse, most developed countries such as the United Kingdom and the United States have made very little progress in the treatment and prevention of drug abuse (Bickel, Moody and Higgins, 2016). This study seeks to evaluate some of the major issues associated with the health economics of substance abuse. Over the years studies have been carried on the given topic, but they have focused mainly on developing or un-developed countries. So, this is a research gap that the topic from the viewpoint of developed countries has not been studied. Therefore, this study aims at filling this gap. As per Atilola, et al (2014) concerns may be different in the developed economic from those in developing economies. According to Edwards and Koob (2013), addiction is characterised by compulsive drug-seeking with longlasting alterations in the brain. Sau et al. (2013) states the ease of access to drugs in cities explains why their use and addiction is higher in urban areas. In recent years substance abuse has become a major issue for the people living in developed nations. This is due to the rapid increase in number of individuals using or rather abusing substances. Such a situation puts significant pressure on the health and economic systems within a country. There is a need to study this aspect and understand it better so that cost pressures can be reduced on the society as well as the health and economic infrastructures in the country. This was the key motivating factor for the current study. 


\section{Methods}

This systematic review searched for evidence on issues of substance abuse in the developed world, which are related to health economics. PubMed, EMBASE, Google Scholar and SAGE Research Methods are the four electronic databases used to search for published article. The use of these four search engines was important in this study because, first, using four as opposed to one or two increases the search frame and therefore increases the probability to get more varied content. As a result, this contributes to the improvement of information validity. Secondly, as opposed to using a general search engine such as Google, using PubMed and EMBASE helps search for publications about health. Articles selected were published between January 2009 and March 2019 and the following keywords were used in the search; Substance abuse, Drug abuse, Drug addiction, Drug-related health issues, Cost of substance abuse, and Drug abuse in developed countries. English-language original research studies were selected including those that provided quantitative and qualitative evidence of one or more determinants of health-economic cost related to substance abuse.

Articles that did not provide original evidence, case histories, reviews, editorials and commentaries were excluded. All titles and abstracts were assessed for inclusion after which the full text was then assessed. A standardised data extraction form was developed. It was piloted on 12 articles, after which, it was revised. Finally, the following information was extracted, both at the pilot stage and at the data collection stage; the first name of the author (s), substance abuse discussed, health economic cost and relationship between substance abuse and the cost discussed.

\section{Results}

The health economics of substance abuse covers a wide variety of issues that stretch from the direct cost related to health concerns of drug abuse to the indirect impact on the productivity of the population affected by drug abuse (Collin and Casswell, 2016; Compton and Berning, 2015; Bickel, Moody and Higgins, 2016). Also, some cases of hepatitis C and HIV infections (over 20\%) are caused by needle sharing during drug use (Centers for Disease Control and Prevention, 2013). Deaths related directly or indirectly to drug abuse are as high as 300,000 each year, a third of these $(30 \%)$ are caused by car accidents resulting from drivers under the influence of drugs (Sauber-Schatz, Thomas, Cook, 2015; Jewett et al., 2015). The US also reports a high crime rate related to drug abuse; about $60 \%$ of federal inmates are in prison for offences that are related to drugs, and over $40 \%$ of all major criminal arrests occur while the perpetrator is under the influence of drugs (Caulkins and Kleiman, 2014). Australia incurs over 2 billion AUD in health costs related to drug abuse. However, over the years Australia has reduced the impact of drug abuse through education and community programs to support people struggling with drug addiction (Csete et al., 2016). In the UK, over 3 billion GBP are spent on health issues caused by drug abuse (Marquez and Saxena, 2016; (Merten et al., 2017).

\section{Discussion}

\section{Addiction and Health}

Drug addiction has become a global trend and is more prevalent in richer countries (King et al., 2014). Addiction to drugs and alcohol is now considered a major public health issue. Abuse of and addiction to drugs have a profound effect on the brain and the nervous system, which 
indicates a heavy impact on public health. Some of the abused drugs are legal prescription drugs (Abuse and Administration Report, 2014), whereas illegal substances are available through illegal production and trafficking. Furthermore, addiction is a critical health issue in that users become physically and psychologically dependent on the drug. A withdrawal syndrome occurs when the addict attempts to stop using the substance. Mild or severe withdrawal symptoms lead to cycles of dependency, further compromising the user's physical and mental wellbeing (American Psychiatric Association, 2013).

The implementation of anti-drug policies has been found inadequate to deal with the problem of addiction and dependency. The reason for this is that other factors also are related to addiction: peer influence, cost, availability, environmental factors, genetic factors and methods of administration. The cost of the substance affects its affordability to the particular group of users. (Abuse and Office of the Surgeon General, 2016). Development and implementation of health policies to combat drug abuse and addiction must focus on any factor that contributes to addiction.

Drug addiction has a direct impact on a person's health, which leads to high costs in terms for treatment, prevention, and morbidity, as well as to death. To support persons affected by drug abuse, governments invest in treatment and prevention, including education. Treatment in rehabilitation centres and educational programs are costly (Csete et al., 2016). Hospital visits that are related to substance abuse result from drug overdose, psychotic episodes, transmission of hepatitis $C$ and $B$ infections by sharing needles to inject drugs, and adverse reactions to drugs. Hospital costs also include cases of drug-related accidents and crimes (American Psychiatric Association, 2013).

Mortality and morbidity resulting from substance use and addiction have high health costs. It has been estimated that the rate of mortality related to drug abuse among users in their mid-thirties is $1.3 \%$. Drug-related morbidity is also very important. This mortality rate is in addition to increased morbidity rate that is associated to drug abuse (Centers for Disease Control and Prevention, 2013). The impact of drug abuse on children has a significant impact on child morbidity. Exposure to drugs during foetal life or when young if either parent is an addict has a significant impact on the children's physical, psychological and emotional health. As a result, these children require additional care, which adds to expenses at both the family and national levels (Patel, et al., 2016).

\section{Public Safety}

Substance abuse and addiction also pose costly and significant risks to public safety. One of these is driving under the influence. The manufacturing of illicit drugs poses a high risk to the public due to illegal disposal of the chemicals and ingredients of the drugs, which leads to environmental contamination and introduction of chemicals used or generated during manufacturing into groundwater and/or sea water. The cost of protecting public health from these hazards is high. Moreover, manufacturing of illicit drugs in residential areas leads to a reduced quality of life resulting from criminal activities, children endangerment and explosions, all of which impose a burden (Bickel, Moody and Higgins, 2016).

Substance abuse is strongly associated with crime, and the cost is long-lasting. Research has reported a high correlation between intimate partner violence and drug abuse. Cantor et al, (2015) reported that on college campuses, drugs and alcohol are the leading risk factors for non- 
consensual sexual contacts. About $55 \%$ of convicted offenders are reported to be under the influence of drugs at the time of the crime. Drug and substance abuse have been linked to economic-compulsive crime. These are crimes committed by perpetrators to support their drug addiction by theft, prostitution and other illegal activities. There is also a link between substance abuse and systematic crime and violence between drug dealers and users. In Australia, the estimated cost related to drug crime is $\$ 3$ billion yearly. In the United State, this cost has been estimated as $\$ 61$ billion annually (Breiding et al., 2015).

\section{Loss in Productivity}

Productivity loss happens mainly when drug users are under the influence or are in treatment or incarceration (Aranda, 2017). While in treatment or hospitals, drug abusers do not participate in training, work and education, which amounts to economic loss. In the United States, productivity loss due to drug abuse has been estimated to be $\$ 120$ billion annually (approximately $0.9 \%$ of gross domestic product) (Florence et al., 2016). In Australia, the estimated loss amounted to $0.3 \%$ of GDP in Australia and $0.4 \%$ in Canada (Gowing et al., 2015).

\section{Conclusion}

Substance abuse and addiction imposes a heavy burden on societies. Drug addiction results in decline in occupational and social functioning, higher morbidity, and early mortality. These issues are quantified into functional life cost or adjusted life years due to disability. In developed countries, drug addiction is a major health concern. The consequent health costs, which are either direct or indirect, form an important part of health economics. These costs are related to criminal activities linked to substance addiction, as well productivity loss and the effect on public safety and public health. These are the major issues that developed countries are encountering due to alcohol and substance abuse. Deaths related directly or indirectly to drug abuse are as high as 300,000 each year, a third of these (30\%) are caused by car accidents resulting from drivers under the influence of drugs. The US also reports a high crime rate related to drug abuse; about $60 \%$ of federal inmates are in prison for offences that are related to drugs, and over $40 \%$ of all major criminal arrests occur while the perpetrator is under the influence of drugs. Australia incurs over 2 billion AUD in health costs related to drug abuse. However, over the years Australia has reduced the impact of drug abuse through education and community programs to support people struggling with drug addiction. In the UK, over 3 billion GBP are spent on health issues caused by drug abuse

\section{Conflict of interest}

The author declares no conflict of interest.

\section{Funding}

No funding was received for this work. 


\section{References}

Abuse, S. (2014). Administration MHS. Results from the 2013 national survey on drug use and health: summary of national findings. NSDUH series H-48, HHS Publication No. (SMA) 144863. Substance Abuse and Mental Health Services Administration: Rockville, MD. Available in https://www.ncbi.nlm.nih.gov/books/NBK519735/.

Office of the Surgeon General US. (2016). Introduction and Overview of The Report. In Facing Addiction in America: The Surgeon General's Report on Alcohol, Drugs, and Health [https://www.ncbi.nlm.nih.gov/books/NBK424860/]. US Department of Health and Human Services.

American Psychiatric Association. (2013). Diagnostic and statistical manual of mental disorders $\left(D S M-5^{\circledR}\right)$. American Psychiatric Pub.

Aranda, J. V. (2017). Paediatric Pharmacology and Drug Therapy, An Issue of Paediatric Clinics of North America, E-Book (Vol. 64, No. 6). Elsevier Health Sciences.

Bickel, W. K., Moody, L., \& Higgins, S. T. (2016). Some current dimensions of the behavioural economics of health-related behavior change. Preventive medicine, 92, 16-23.

Breiding, M. J., Smith, S. G., Basile, K. C., Walters, M. L., Chen, J., \& Merrick, M. T. (2015). Prevalence and characteristics of sexual violence, stalking, and intimate partner violence victimization-National Intimate Partner and Sexual Violence Survey, United States, 2011. American journal of public health, 105(4), E11.

Cantor, D., Fisher, B., Chibnall, S. H., Townsend, R., Lee, H., Thomas, G., ... \& Westat, Inc. (2015). Report on the AAU campus climate survey on sexual assault and sexual misconduct.

Caulkins, J. P., and Kleiman, M. (2014). How Much Crime is Drug-related? History, Limitations, and Potential Improvements of Estimation Methods. National Criminal Justice Reference Service.

Centers for Disease Control and Prevention. (2013). Alcohol and public health: Alcohol-related disease impact (ARDI).

Collin, J., \& Casswell, S. (2016). Alcohol and the sustainable development goals. The Lancet, 387(10038), 2582-2583.

Compton, R. P., \& Berning, A. (2015). Drug and alcohol crash risk. Journal of Drug Addiction, Education, and Eradication, 11(1), 29.

Csete, J., Kamarulzaman, A., Kazatchkine, M., Altice, F., Balicki, M., Buxton, J., ... \& Hart, C. (2016). Public health and international drug policy. The Lancet, 387(10026), 1427-1480.

Dobkin, C., and Nicosia, N. (2009). The war on drugs: methamphetamine, public health, and crime. American Economic Review, 99(1), pp.324-49.

Edwards, S., and Koob, G. F. (2013). Escalation of drug self-administration as a hallmark of persistent addiction liability. Behavioural pharmacology, 24.

Florence, C., Luo, F., Xu, L., and Zhou, C. (2016). The economic burden of prescription opioid overdose, abuse and dependence in the United States, 2013. Medical care, 54(10), p.901.

Gowing, L. R., Ali, R. L., Allsop, S., Marsden, J., Turf, E. E., West, R., and Witton, J. (2015). Global statistics on addictive behaviours: 2014 status report. Addiction, 110(6), pp.904-919.

Jewett, A., Shults, R. A., Banerjee, T., \& Bergen, G. (2015). Alcohol-impaired driving among adultsUnited States, 2012. MMWR. Morbidity and mortality weekly report, 64(30), 814. 
King, N. B., Fraser, V., Boikos, C., Richardson, R., and Harper, S. (2014). Determinants of increased opioid-related mortality in the United States and Canada, 1990-2013: a systematic review. American journal of public health, 104(8), pp.e32-e42.

Kwako, L. E., and Koob, G. F. (2017). Neuroclinical framework for the role of stress in addiction. Chronic Stress, 1, p.2470547017698140.

Marquez, P. V., \& Saxena, S. (2016). Making mental health a global priority. In Cerebrum: The Dana forum on brain science (Vol. 2016). Dana Foundation.

Merten, E. C., Cwik, J. C., Margraf, J., \& Schneider, S. (2017). Overdiagnosis of mental disorders in children and adolescents (in developed countries). Child and adolescent psychiatry and mental health, 11(1), 5.

Miller, J. (2018). The War on Drugs 2.0: Darknet Fentanyl's Rise and the Effects of Regulatory and Law Enforcement Action. Available at SSRN 3344593.

Patel, V., Chisholm, D., Parikh, R., Charlson, F. J., Degenhardt, L., Dua, T., ... \& Lund, C. (2016). Addressing the burden of mental, neurological, and substance use disorders: key messages from Disease Control Priorities. The Lancet, 387(10028), 1672-1685.

Sauber-Schatz, E. K., Thomas, A. M., \& Cook, L. J. (2015). Motor vehicle crashes, medical outcomes, and hospital charges among children aged 1-12 years-Crash Outcome Data Evaluation System, 11 states, 2005-2008. Morbidity and Mortality Weekly Report: Surveillance Summaries, 64(8), 1-32. 